\title{
Astronomy in Mozambique
}

\author{
Valério A. R. M. Ribeiro ${ }^{1}$ and Cláudio M. Paulo ${ }^{2}$ \\ ${ }^{1} \mathrm{UCT}$, South Africa ${ }^{2} \mathrm{UEM}$, Mozambique
}

\begin{abstract}
We present the state of Astronomy in Mozambique and how it has evolved since 2009 following the International Year of Astronomy. Activities have been lead by staff at University Eduardo Mondlane and several outreach activities have also flourished. In 2010 the University introduced its first astronomy module, Introduction to Astronomy and Astrophysics, for the second year students in the Department of Physics. The course has now produced the first students who will be graduating in late 2012 with some astronomy content. Some of these students will now be looking for further studies and those who have been keen in astronomy have been recommended to pursue this as a career. At the university level we have also discussed on the possibility to introduce a whole astronomy course by 2016 which falls well within the HCD that the university is now investing in. With the announcement that the SKA will be split between South Africa with its partner countries (including Mozambique), and Australia we have been working closely with the Ministry of Science and Technology to make astronomy a priority on its agenda. In this respect, an old telecommunications antenna is being converted by the South Africa SKA Project Office, and donated to Mozambique for educational purposes. It will be situated in Maluana, Mozambique.
\end{abstract}

